Artículo original

\title{
Mutaciones del gen ARN ribosómico 235 de Helicobacter pylori asociadas con resistencia a claritromicina en pacientes atendidos en una unidad de endoscopia de Medellín, Colombia
}

\author{
Ingrid Johana Roldán, Rodrigo Castaño, María Cristina Navas
}

Grupo de Gastrohepatología, Facultad de Medicina, Universidad de Antioquia, Medellín, Colombia

Introducción. La claritromicina es el antibiótico de primera línea para el tratamiento de la infección por Helicobacter pylori. La resistencia bacteriana se produce principalmente por mutaciones puntuales del gen ARN ribosómico 23S (ARNr 23S).

Objetivo. Determinar la frecuencia de las mutaciones puntuales A2143G y A2142G del gen ARNr 23S asociadas con la resistencia de $H$. pylori a la claritromicina en muestras de pacientes con manifestaciones dispépticas en Medellín, región noroccidental de Colombia. Materiales y métodos. Se extrajo ADN a partir de muestras de biopsia gástrica obtenidas de pacientes con manifestaciones dispépticas atendidos en una unidad de endoscopia entre el 2016 y el 2017. Mediante reacción en cadena de la polimerasa (PCR), se amplificaron las regiones $s$ y $m$ del gen vacA y una región del gen ARNr $23 S$ bacteriano. La presencia de las mutaciones A2142G y A2143G se determinó por la técnica de polimorfismos de longitud de fragmentos de restricción (RFLP) con las enzimas Bbsl y Bsal, respectivamente.

Resultados. Se encontró una prevalencia de infección de 44,2 \% (175/396), según el informe de histopatología. En 143 de estas 175 muestras positivas se amplificaron las tres regiones del genoma bacteriano. Se identificaron las mutaciones A2143G y A2142G en 27 muestras (18,8 \%; 27/143), la mutación más frecuente fue la A2143G (81,5\%; 22/27).

Conclusiones. Hubo una gran prevalencia de mutaciones asociadas con la resistencia de $H$. pylori a la claritromicina en la población de estudio. Se requieren estudios adicionales para establecer la resistencia bacteriana en la población colombiana y, así, determinar los tratamientos de primera línea y de rescate.

Palabras clave: Helicobacter pylori; farmacorresistencia bacteriana; claritromicina; neoplasias gástricas.

Recibido: 06/03/18

Aceptado: 29/01/19

Publicado: 06/02/19

Citación:

Roldán IJ, Castaño R, Navas MC. Mutaciones del gen $23 S$ del ARN ribosómico de Helicobacter pylori asociadas con resistencia a claritromicina en pacientes atendidos en una unidad de endoscopia de Medellín, Colombia. Biomédica. 2019;39(Supl.2):117-29. https://doi.org/10.7705/biomedica.v39i4.4377

\section{Correspondencia:}

María Cristina Navas, Grupo de Gastrohepatología, Facultad de Medicina, Universidad de Antioquía, Calle $70 N^{\circ} 52-21$, Medellín, Colombia

Teléfono: (574) 219 6563; fax: (574) 2196565

maria.navas@udea.edu.co

Contribución de los autores:

Ingrid Johana Roldán: análisis de muestras Rodrigo Castaño: obtención de muestras

Todos los autores participaron en el diseño del estudio, en el análisis e interpretación de los resultados y en la redacción del manuscrito.

Financiación:

Financiado por el proyecto de sostenibilidad,

Vicerrectoría de Investigación, Universidad de Antioquia

Conflicto de intereses:

Los autores declaran no tener ningún tipo de conflicto de intereses.

\section{Mutations in the Helicobacter pylori 23S rRNA gene associated with clarithromycin} resistance in patients at an endoscopy unit in Medellín, Colombia

Introduction: Clarithromycin is the first-line antibiotic for the treatment of Helicobacter pylori infection. Bacterial resistance is mainly due to the presence of specific mutations in the 23S ribosomal RNA (rRNA) gene.

Objective: To determine the frequency of $A 2143 G$ and $A 2142 G$ specific mutations in the 23S rRNA gene associated with clarithromycin resistance of $H$. pylori in samples from patients with dyspeptic manifestations in Medellín, northwestern Colombia.

Materials and methods: DNA was extracted from gastric biopsy samples of patients with dyspeptic manifestations seen at an endoscopy unit in Medellín between 2016 and 2017. PCR was performed to amplify the bacterial $s$ and $m$ vacA regions, and a region in the $23 S$ rRNA gene. The presence of the $A 2142 G$ and $A 2143 G$ mutations was determined using the restriction fragment length polymorphism (RFLP) technique with the Bbsl and Bsal enzymes, respectively. Results: The prevalence of infection was $44.2 \%$ (175/396), according to the histopathology report. The positive samples were analyzed and the three regions of the bacterial genome were amplified in 143 of the 175 samples. The A2143G and A2142G mutations were identified in 27 samples (18.8\%, 27/143). The most frequent mutation was A2143G (81.5\%, 22/27). Conclusions: We found a high prevalence of $H$. pylori mutations associated with clarithromycin resistance in the study population. Further studies are required to determine the bacterial resistance in the Colombian population in order to define first line and rescue treatments.

Keywords: Helicobacter pylori; drug resistance, bacterial; clarithromycin; stomach neoplasms.

Helicobacter pylori es un bacilo Gram negativo que pertenece a la familia Helicobacteraceae y existe en dos formas, espiral y cocoide; tiene múltiples flagelos unipolares y codifica enzimas como catalasa, oxidasa y ureasa, las cuales le permiten adaptarse a las condiciones del epitelio gástrico. Es una bacteria microaerófila y exigente en cuanto a la nutrición, lo que dificulta su cultivo in vitro $(1,2)$. 
En la mayoría de los casos, $H$. pylori se adquiere en el entorno familiar por vía oral-oral y fecal-oral durante los primeros cinco años de vida (3). Se estima que el $50 \%$ de la población mundial está infectado con el microorganismo. En los países en desarrollo, la prevalencia de la infección en la población general varía entre 60 y $90 \%$, mientras que en los países desarrollados está entre el 25 y el $50 \%$, lo que refleja la importancia de los factores socioeconómicos como determinantes de su prevalencia $(4,5)$.

Helicobacter pylori coloniza de forma selectiva el epitelio gástrico. En la mayoría de las personas la infección es asintomática; sin embargo, puede desencadenar una inflamación crónica y producir una úlcera péptica en cerca del $10 \%$ de las personas. Dos neoplasias se han asociado con la infección por $\mathrm{H}$. pylori, el linfoma del tejido linfoide asociado con la mucosa (MucosaAssociated Lymphoid Tissue, MALT), que se presenta en el 0,1\% de los casos, y el adenocarcinoma gástrico, presente en 1 a $3 \%$ de los pacientes, y que constituye la quinta neoplasia más frecuente en el mundo (6-8).

El tratamiento para erradicar la infección por $H$. pylori previene el desarrollo de afecciones gastroduodenales. El esquema recomendado a nivel mundial incluye un inhibidor de la bomba de protones y dos tipos de antimicrobianos. En el tratamiento de primera línea, se utilizan con mayor frecuencia la amoxicilina y la claritromicina, y en el de segunda línea, se emplea la amoxicilina y la levofloxacina. Sin embargo, la gran resistencia a estos antibióticos ha dificultado la erradicación de la infección (9).

El principal mecanismo de resistencia de $H$. pylori a la claritromicina es la disminución de la afinidad del macrólido con la subunidad $50 S$ del ribosoma bacteriano debida a mutaciones puntuales en nucleótidos adyacentes al dominio $V$ del gen ARNr $23 S(10,11)$. Las mutaciones más comunes se han reportado en las posiciones 2142 y 2143, con sustituciones de adenina (A) por guanina (G) (A2142G y A2143G) o de A por citosina (C) (A2142C); también, se ha registrado la sustitución $\mathrm{A} 2144 \mathrm{G}$, aunque con menor frecuencia (12-15). El desarrollo de la resistencia se ha visto favorecido por el incumplimiento del tratamiento y el uso de macrólidos en el tratamiento de otras infecciones, principalmente de las vías respiratorias (16).

Colombia cuenta con un único estudio que evalúa la prevalencia global de infección por $H$. pylori. Bravo, et al., informaron de una prevalencia de $69,1 \%$ en 8.652 informes histopatológicos de endoscopias de pacientes con manifestaciones dispépticas en 16 hospitales regionales de las zonas suroccidental, norte, centro, centro-occidental y oriental del país, la cual varió entre las regiones en un rango entre 41,7 y $99,1 \%$ (17).

A nivel nacional, la elevada prevalencia de infección se correlaciona con la incidencia, también elevada, del adenocarcinoma gástrico, que entre 2010 y 2014 fue la primera causa de muerte por cáncer en hombres y la tercera en mujeres, con tasas de mortalidad de 16,84 y 8,73 por 100.000 habitantes, respectivamente $(18,19)$.

La infección por $H$. pylori tienen un gran impacto en la vida de los individuos afectados y en el sistema de salud, por lo cual son muy importantes su diagnóstico y tratamiento (20). Los esquemas terapéuticos deben sustentarse en estudios de la resistencia a nivel local por la heterogeneidad de su presentación en diferentes poblaciones. No obstante, en Colombia se siguen prescribiendo tratamientos basados en estudios de otros países (21) y, además, esquemas que han perdido eficacia debido a la 
resistencia bacteriana, aunque los más utilizados sean mencionados en el consenso de Maastricht $(9,22)$.

En un metaanálisis de la resistencia de $H$. pylori en Latinoamérica, Camargo, et al., señalan una resistencia a la claritromicina del $18 \%$ (rango: entre 2,7 y $60 \%$ ) en Colombia, según estudios en Bogotá, Pereira, Armenia, Tumaco, Túquerres y Manizales, lo que sugiere que es uno de los países con mayor prevalencia de resistencia en Latinoamérica (23). Ello implica que debe evaluarse la sensibilidad de la bacteria a otros antibióticos, con el fin de establecer esquemas de primera línea y de rescate, dado que los antibióticos útiles para tratar la infección son pocos $(21,24)$.

La resistencia de $H$. pylori a la claritromicina se ha comprobado en los estudios de efectividad del tratamiento antibiótico. Castaño, et al., por ejemplo, compararon dos esquemas de tratamiento estándar con claritromicina, uno de 7 días y otro de 10, administrados a pacientes de Medellín; encontraron que las tasas de erradicación en el análisis por intención de tratar, determinadas mediante una prueba de aliento optimizada, fueron de 67,8 y $74,3 \%$, respectivamente, sin diferencias estadísticamente significativas; estos porcentajes están por debajo de los niveles óptimos de erradicación (25). Posteriormente, los mismos autores compararon el tratamiento estándar con claritromicina y uno con levofloxacina durante 10 días, y determinaron una diferencia significativa en la eficacia de los dos esquemas a favor de la levofloxacina (26).

En Medellín, la prevalencia de infección por $H$. pylori en pacientes sintomáticos oscila entre 36,4 y $65 \%$; sin embargo, se desconoce la prevalencia de la resistencia de esta bacteria a la claritromicina $(17,27)$.

El objetivo de este estudio fue determinar la frecuencia de las mutaciones puntuales A2143G y A2142G del gen ARNr 23S asociadas con la resistencia de $H$. pylori a la claritromicina en biopsias gástricas de pacientes con manifestaciones dispépticas atendidos en una unidad de endoscopia de Medellín.

\section{Materiales y métodos}

\section{Población de estudio}

Se hizo un estudio descriptivo transversal entre pacientes mayores de 18 años con manifestaciones dispépticas atendidos en una unidad de endoscopia de la IPS SURA (Sede Industriales de Medellín) entre febrero de 2016 y abril de 2017. Esta unidad de atención es de segundo nivel de complejidad y atiende mayoritariamente a pacientes de estratos 4 a 6 que cuentan con plan de medicina prepagada.

Se calculó un tamaño de muestra de 175 pacientes con base en una prevalencia de resistencia estimada del $16 \%$ para la población colombiana, con un intervalo de confianza del $95 \%$ y un error del $5 \%$.

Los pacientes incluidos en el estudio no habían recibido tratamiento con inhibidores de la bomba de protones o antibióticos en el mes previo a la toma de la muestra. Se excluyeron aquellos con diagnóstico de cáncer, enfermedad terminal o gastrectomías previas.

A cada uno de los pacientes se le explicó el estudio y, en caso de que aceptara participar, se solicitaba la firma del consentimiento informado. 
Se tomaron cinco biopsias gástricas para el estudio histopatológico siguiendo el protocolo de Sidney: las curvaturas mayor y menor del antro y del cuerpo, y la incisura angular (28); se tomó una biopsia adicional del antro para el estudio molecular, por ser esta la región del estómago con mayor densidad bacteriana en casos de infección $H$. pylori (29). La muestra del antro se colocó en un tubo plástico estéril de $1,5 \mathrm{ml}$ con caldo de infusión cerebro-corazón (BHI, BD, Sparks, MD, USA) y glicerol al $20 \%$. Las muestras se refrigeraron a $4{ }^{\circ} \mathrm{C}$ y se transportaron hasta el Laboratorio de Gastrohepatología de la Universidad de Antioquia el mismo día del procedimiento endoscópico, donde se conservaron a $-70^{\circ} \mathrm{C}$ hasta su procesamiento.

\section{Consideraciones éticas}

El proyecto fue aprobado por el Comité de Bioética de Investigación en Humanos de la Sede de Investigación Universitaria de la Universidad de Antioquia.

\section{Extracción de ADN y amplificación por PCR}

Todas las biopsias obtenidas se sometieron a análisis histopatológico y se tiñeron con la coloración estándar de hematoxilina y eosina. El análisis del $70 \%$ de las muestras, aproximadamente, estuvo a cargo de un patólogo especializado en el tubo digestivo y el $30 \%$ restante de las muestras fue evaluado por otros patólogos.

De las muestras positivas para $H$. pylori según el informe de histopatología, se obtuvo ADN total utilizando un estuche comercial (QIAamp DNA Mini Kit' ${ }^{\mathrm{TM}}$, Qiagen, Alemania) y siguiendo las instrucciones del fabricante. El material obtenido se cuantificó (NanoDrop 2000 ${ }^{\mathrm{TM}}$, Thermo Scientific, USA).

Para determinar la presencia de la bacteria en la muestra, se amplificaron las regiones $\mathrm{s}$ y $\mathrm{m}$ del gen vacA utilizando los cebadores descritos por Acosta, et al., vacA s: F 5'-ATGGAAATACAACAAACACAC-3' y R 5'-CTGCTTGAATGCGCCAAAC-3'; vacA m: F '-CAATCTGTCCAATCAAGCGAG-3' y R 5'-GCGTCTAAATAATTCCAAGG-3' (30). En aquellas muestras positivas para las regiones $s$ y $m$ del gen vacA, se amplificó una región del gen $A R N r 23 S$ para determinar la presencia de mutaciones, empleando los cebadores descritos previamente por Occhialini, et al.: K1 5'-CCACAGCGATGTGGTCTCAG-3' y K2 5'-CTCCATAAGAGCCAAAGCCC-3' (31).

Cada una de las tres reacciones de PCR se llevaron a cabo en un volumen final de $25 \mu$ que contenía $1 \mathrm{X}$ de tampón, $1,5 \mathrm{mM}$ de $\mathrm{MgCl}_{2}, 0,2$ $\mathrm{mM}$ de dNTP, 0,4 mM de cada cebador, 2,5 $\mathrm{U}$ del reactivo Biolasa ${ }^{\mathrm{TM}^{2}}$ (Bioline, Reino Unido) y $2 \mu \mathrm{l}$ del ADN extraído.

En un termociclador (C1000 Touch ${ }^{\mathrm{TM}}$, Thermal Cycler) se programó un ciclo inicial de desnaturalización a $94^{\circ} \mathrm{C}$ durante dos minutos seguido de 35 ciclos de amplificación con variaciones según la región de interés: a $94^{\circ} \mathrm{C}$ durante un minuto, a $55^{\circ} \mathrm{C}$ durante un minuto y a $72{ }^{\circ} \mathrm{C}$ durante un minuto para la región s del vacA; a $94^{\circ} \mathrm{C}$ durante un minuto, a $52{ }^{\circ} \mathrm{C}$ durante un minuto y a $72^{\circ} \mathrm{C}$ durante un minuto para la región m del gen vacA, y a $94{ }^{\circ} \mathrm{C}$ durante 30 segundos, a $60^{\circ} \mathrm{C}$ durante 30 segundos y a $72{ }^{\circ} \mathrm{C}$ durante 30 segundos para la región ARNr $23 \mathrm{~S}$, con un ciclo final a $72^{\circ} \mathrm{C}$ durante cinco minutos.

Los productos de amplificación se sometieron a electroforesis en geles de agarosa al 2,5\% teñidos con bromuro de etidio. Para la estandarización de las PCR, se utilizó ADN genómico de la cepa NCTC 11637 de H. pylori como control positivo (gentilmente donado por Dra. Alba Alicia Trespalacios, profesora de la 
Pontificia Universidad Javeriana) y, como control negativo se usó agua destilada estéril. Es de anotar que la cepa NCTC 11637 no presenta mutaciones en los nucleótidos 2142 y 2143 y, por lo tanto, no se incluyó en los ensayos de RFLP.

En la técnica de polimorfismos de longitud de fragmentos de restricción (Restriction Fragment Length Polymorphism, RFLP) se utilizaron las enzimas de restricción Bbsl y Bsal (New England Biolabs, USA) y 3,5 $\mu \mathrm{l}$ del producto de PCR del gen ARNr 23S en un volumen final de $20 \mu$ l, según las instrucciones del fabricante.

Cuando la mutación A2142G está presente, la digestión de los amplicones de la región de la peptidiltransferasa del gen ARNr $23 \mathrm{~S}$ con la enzima Bbsl genera dos fragmentos de 93 y 332 pares de bases, aproximadamente, en tanto que, con la enzima Bsal (A2143G), produce tres fragmentos de 20, 300 y 105 pares de bases (GenBank U27270).

Como control positivo de los RFLP se incluyeron amplicones del fragmento de lectura abierta (Open Reading Frame, ORF) Core del virus de la hepatitis B (HBV) obtenidos a partir del plásmido pJET-TH24_1,5 (GenBank FJ589065) (32). La amplificación de esta región genera un fragmento de 748 pb, aproximadamente, que fue sometido a digestión con la enzima Bbsl para generar dos fragmentos de 608 y 140 pb, y con la enzima Bsal, para producir dos fragmentos de 508 y $240 \mathrm{pb}$. Esta secuencia fue seleccionada mediante mapeo de restricción utilizando la herramienta BioEdit, versión 7.1.9. Los amplicones del ORF Core del HBV (nucleótidos 1098 a 1846) se incluyeron en todos los ensayos de RFLP (figura 1).

Se seleccionaron al azar 18 (12,5\%) muestras positivas en el estudio de histopatología para evaluar la reproducibilidad de los resultados de PCR de las tres regiones (vacA s y m y ARNr 23S) y del método de RFLP.

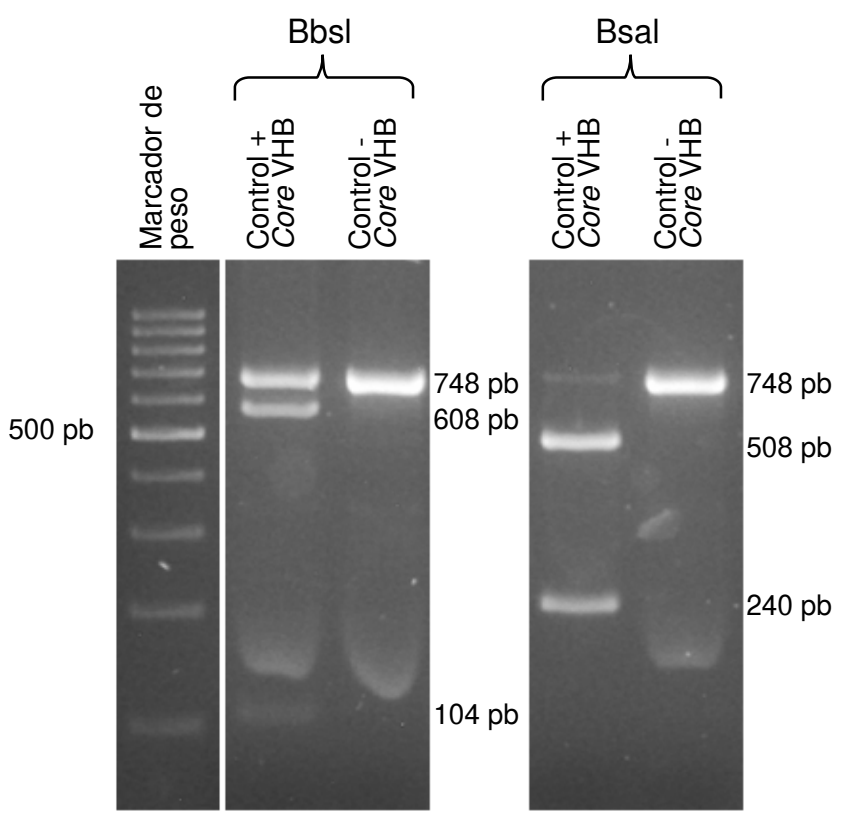

Figura 1. Electroforesis de $A D N$ en gel de agarosa al $2,5 \%$ teñido con bromuro de etidio. Se observan las bandas obtenidas mediante la técnica de RFLP con el control positivo del ORF Core del HBV. 
Además, 10 biopsias con resultado negativo en el estudio de histopatología se analizaron mediante PCR para verificar la presencia de vacA y del gen ARNr 23S, y aquellas con resultado positivo en dicho estudio, pero que no amplificaron para vacA s y m y ARNr 23S, se analizaron mediante PCR con el fin de verificar la integridad del genoma, utilizando los siguientes cebadores para el gen de la gliceraldehído-3-fosfato deshidrogenasa (GAPDH): 5'-CCTTCATTGACCTCAACTACATGG-3' y 5'-AGTCTTCTGGGTGGCAGTGATGG-3.

\section{Resultados}

Durante el periodo comprendido entre febrero de 2016 y abril de 2017, 588 pacientes remitidos para endoscopia por síntomas dispépticos acudieron a la IPS Sura de Medellín. Se invitó a participar en el estudio a 403 (68,5\%) de estos pacientes, y 396 de ellos aceptaron; siete se excluyeron por presentar antecedentes de cáncer gástrico o consumo de antibióticos, o por no estar de acuerdo con el estudio. El 59 \% (234/396) de los participantes en el estudio eran mujeres, el rango de edad fue de 18 a 86 años, con un promedio de $48( \pm 14)$ años.

De los 396 casos incluidos en el estudio, 175 fueron positivos para la infección por H. pylori según la evaluación histopatológica con hematoxilina y eosina, es decir, una prevalencia de infección del 44,2\% (175/396). Es de anotar que no se utilizaron otros métodos de diagnóstico, como la prueba rápida de la ureasa y la de aliento con urea, pues no son exámenes de rutina en casos de dispepsia en esta unidad de atención.

De las 175 muestras positivas para H. pylori por histopatología, en 143 (82\%) se obtuvo la amplificación de las regiones $\mathrm{s}$ y $\mathrm{m}$ del gen vacA y de la región del gen ARNr 23S (figura 2). El gen vacA es un factor de virulencia que se encuentra presente en todas las cepas de $H$. pylori y su utilidad para demostrar esta bacteria en muestras biológicas es comparable con la de otros genes bacterianos, como ureA, ureC, ARNr 16S, ARN 23S y Hsp60 $(30,33,34)$.

En 27 de 143 (18,8\%) muestras analizadas, el método de RFLP permitió identificar las mutaciones puntuales A2143G y A2142G en el gen ARNr $23 S$ de H. pylori (figuras 2 y 3 ).

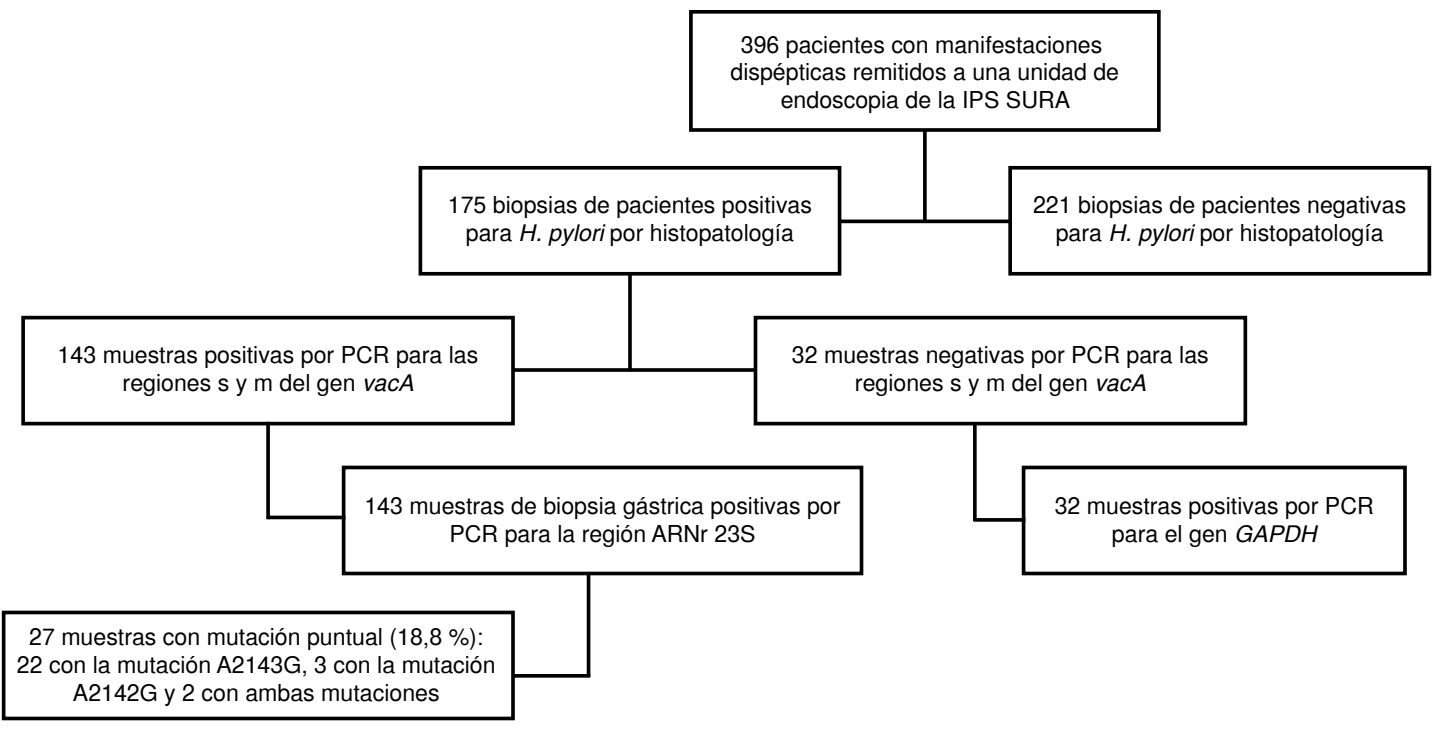

Figura 2. Diagrama de los procedimientos y resultados obtenidos para las biopsias gástricas procesadas en el estudio 


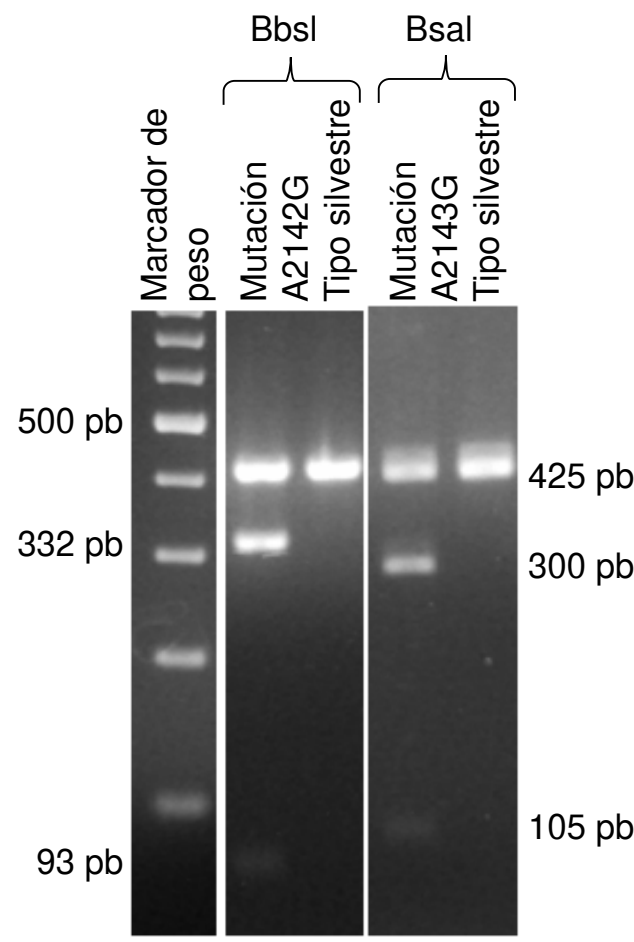

Figura 3. Electroforesis de ADN en gel de agarosa al 2,5\% teñido con bromuro de etidio. Se observan las bandas obtenidas con la técnica de RFLP en presencia de las mutaciones A2143G y A2142G.

Las sustituciones más frecuentes fueron la A2143G en 22 de 27 muestras (81,5\%) y la A2142G en 3 de 27 (11\%); en 2 de 27 (7,4\%) de las muestras se encontraron simultáneamente estas dos mutaciones (figura 2). En el cuadro 1 se presentan las variables demográficas de los pacientes con muestras positivas para la infección por $H$. pylori detectada mediante PCR.

La información de seguimiento de los pacientes no estaba disponible, por lo tanto, no se logró establecer si había correlación entre la presencia de mutaciones y la resistencia al tratamiento.

El $81 \%(116 / 143)$ de las muestras analizadas en las que se logró la amplificación de las secuencias del genoma bacteriano, no presentaba las mutaciones puntuales asociadas con la resistencia a la claritromicina. Las 18 muestras analizadas por duplicado mediante PCR para las tres regiones del genoma bacteriano, vacA s y m y ARNr 23S, y mediante el método de RFLP, demostraron una reproducibilidad del $100 \%$. Asimismo, en ninguna de las 10 muestras negativas para infección por $H$. pylori en el estudio histopatológico, se logró amplificar las regiones de interés del genoma bacteriano (no se incluyen los datos).

Cuadro 1. Variables demográficas de pacientes con manifestaciones dispépticas y muestras positivas para la infección por H. pylori mediante PCR atendidos en una unidad de endoscopias de Medellín

\begin{tabular}{lcc}
\hline \multirow{2}{*}{ Característica } & \multicolumn{2}{c}{ Mutaciones A2143G y A2142G } \\
\cline { 2 - 3 } & Presencia n (\%) & Ausencia n (\%) \\
\hline Sexo & & \\
$\quad$ Mujer & $16(59)$ & $60(52)$ \\
Hombre & $11(41)$ & $56(48)$ \\
Edad (años) & & \\
18 a 35 & $6(22)$ & $44(38)$ \\
36 a 50 & $11(41)$ & $30(26)$ \\
51 a 72 & $10(37)$ & $42(36)$ \\
Total & 27 & 116 \\
\hline
\end{tabular}




\section{Discusión}

Según el informe de histopatología, la prevalencia de infección por $H$. pylori en la población de estudio atendida en la unidad de estudio de Medellín entre el 2016 y el 2017, fue de 44,2\%. Esta prevalencia es similar a la descrita en un estudio retrospectivo en muestras obtenidas de pacientes con síntomas dispépticos atendidos en la Clínica Diagnóstica VID de Medellín entre el 2012 y el 2013 (36,4 \%; 986/2708), estudio en que el diagnóstico de infección por $H$. pylori también se determinó por histopatología (27).

Sin embargo, los resultados de ambos estudios muestran una disminución de la prevalencia de infección por H. pylori, en comparación con la prevalencia de $65 \%$ según los informes de histopatología de 494 pacientes de un hospital público de Medellín en 1997 (17). Esta disminución obedecería al mejoramiento de las condiciones sanitarias de la población en las últimas dos décadas, así como al acceso a agua potable y la recolección y el tratamiento de aguas residuales (5).

Dadas las dificultades técnicas que implica el aislamiento de la bacteria, el estudio de histopatología se considera una de las técnicas de referencia para el diagnóstico de la infección por $H$. pylori (1). Para garantizar la menor probabilidad de falsos negativos, se debe hacer un muestreo estandarizado, como el descrito en el protocolo de Sidney; además, se debe restringir el consumo de antibióticos e inhibidores de la bomba de protones por lo menos 30 días antes de la endoscopia (35), con el fin de obtener una mejor sensibilidad y especificidad diagnóstica en comparación con otros métodos directos, como la prueba rápida de la ureasa, la prueba de aliento con urea o la PCR $(36,37)$.

Al considerar las dificultades técnicas para el cultivo de la bacteria, la amplificación mediante PCR a partir de la biopsia gástrica es una metodología que permite la detección de secuencias de $H$. pylori; la sensibilidad de la PCR para $H$. pylori se calcula en 20 copias del gen de interés por muestra (38).

Para determinar la resistencia de $H$. pylori a la claritromicina, se han implementado diversas técnicas, como la difusión en agar, la prueba de epsilometría, la hibridación fluorescente in situ (Fluorescent in situ Hybridization, FISH), la RFLP y la PCR en tiempo real (15). Se ha descrito una correlación entre la detección de las mutaciones puntuales A2142G y A2143G, y la resistencia a la claritrominicina determinada por el aumento de la concentración inhibitoria mínima (CIM) en el cultivo al utilizar la técnica de dilución en agar $(12,13,39)$. El método de RFLP es más rápido y económico que otros métodos cualitativos, como la secuenciación y el FISH, y tiene una especificidad de $88 \%$, una sensibilidad de $85 \%$, un valor predictivo positivo de $54 \%$ y un valor predictivo negativo de $97 \%$ comparado con el cultivo (13). Por ello, esta técnica representa una excelente opción frente a la dificultad técnica del aislamiento de H. pylori (40-42). Además, la técnica de RFLP puede emplearse en biopsias embebidas en parafina (43).

En el presente estudio, la resistencia genotípica de $H$. pylori a la claritromicina en la población fue de $18,8 \%$. Este porcentaje es similar al registrado en pacientes atendidos en instituciones de salud en otras ciudades de Colombia. Trespalacios, et al., reportaron una resistencia de 13,6\% en 256 muestras de pacientes atendidos en un hospital de Bogotá entre el 2009 y el 2011. La resistencia se evaluó utilizando la técnica de dilución en agar y se confirmó por secuenciación de la región del ARNr $23 S$ bacteriano, encontrándose, por lo menos, una de las tres mutaciones (A2143G, A2142G 
o A2142C) en las muestras que presentaban un aumento de la CIM (14). En estudios previos, se reportó una resistencia de 15 a 17,7\% en muestras de pacientes dispépticos atendidos en instituciones de salud de Bogotá entre el 2007 y el 2009, según los resultados obtenidos mediante la prueba de epsilometría y el método de difusión en disco, respectivamente $(16,44)$.

En un estudio reciente en un hospital en Tumaco (suroccidente de Colombia), se determinó una resistencia de 19,8\% mediante la técnica de dilución en agar en 203 muestras analizadas (45). Sin embargo, en otros dos estudios en Bogotá se han descrito frecuencias más altas de resistencia a la claritromicina. En el primero de estos, en 115 pacientes de una unidad de gastroenterología durante el 2008, se determinó una frecuencia de resistencia primaria de $60 \%$ mediante la técnica de difusión en disco, lo que representa el dato de resistencia más alto de H. pylori a claritromicina descrito hasta el momento en el país (46). En un segundo estudio, se detectó resistencia a claritromicina en el 39,2\% (42/107) de las muestras mediante la técnica de dilución en agar. La resistencia fenotípica fue confirmada por PCR de alelo específico (Allele-Specific Polymerase Chain Reaction) en todos los aislamientos resistentes y se identificaron las mutaciones A2143G o A2142G (12).

Por otra parte, la resistencia a este macrólido ha estado por debajo del $5 \%$ en pacientes de otras ciudades del país. En la región del eje cafetero (Pereira, Armenia y Manizales), se describió una prevalencia de 3,8 \% en 106 muestras analizadas por la técnica de la prueba de epsilometría, de las cuales, tres presentaban la mutación A2143G y, una, la sustitución A2142G en el análisis mediante PCR-RFLP $(47,48)$.

Acosta, et al., evaluaron la frecuencia de mutaciones asociadas con la resistencia por secuenciación directa en 162 muestras de pacientes atendidos en un hospital de Popayán (suroccidente de Colombia); el $4,3 \%(7 / 162)$ de las muestras presentaba mutación y de estas, cuatro correspondían a la sustitución A2143G y tres a A2142G (30). Bustamante, et al., encontraron el porcentaje más bajo de resistencia de $H$. pylori a la claritromicina reportado en el país, 2,7 \%; este estudio se hizo en 149 aislamientos obtenidos de 206 pacientes atendidos en un hospital en Túquerres (suroccidente de Colombia) mediante la técnica de dilución en agar (49). En estos estudios, la mutación puntual más frecuente fue la A2143G, lo que coincide con los hallazgos del presente estudio (81,5\%).

En 116 de las 143 muestras analizadas en otro estudio, no se detectaron mutaciones puntuales; sin embargo, esto no excluye la resistencia bacteriana a este macrólido debida a otras mutaciones $u$ otros mecanismos, como las bombas de eflujo (39).

En 32 de las 175 biopsias gástricas positivas por histopatología en el presente estudio, no se logró amplificar ninguna de las tres regiones del genoma bacteriano (regiones $s$ y $m$ del gen vacA y una región del gen $A R N r$ 23S) mediante PCR y debe anotarse que se descartaron inhibidores de la PCR mediante la amplificación del gen GAPDH (no se incluyen los datos). La discordancia entre el resultado de histopatología y el de la PCR se explicaría por la diferencia entre el número de muestras analizadas por histopatología (cinco biopsias provenientes de diferentes regiones del estómago) y por PCR (una biopsia del antro), lo que aumentó la probabilidad de detectar los bacilos mediante histopatología. 
Según el metaanálisis de Camargo, et al., en estudios realizados en Argentina, Cuba, Ecuador, Brasil, Chile, Colombia, Costa Rica, México, Perú y Venezuela, la prevalencia de resistencia de $H$. pylori a este macrólido presentó un rango de 6 a $18 \%$ y Colombia fue el país con el porcentaje más alto (18\%) (23). En estudios más recientes, Squarcio, et al., registraron un porcentaje de resistencia del 16,9\% (83/490) mediante métodos moleculares en diferentes regiones de Brasil; la mutación A2143G se encontró en el $90,4 \%$ de los aislamientos resistentes (50). En Argentina, Zerbetto, et al., encontraron una prevalencia de la resistencia del $26,9 \%$, y la mutación más frecuente fue la A2143G, presente en el 89,4\% de los aislamientos resistentes (51). En México se determinó un porcentaje de resistencia del $17,8 \%$ mediante la técnica de difusión en disco en 45 muestras y se detectó la mutación A2143G en 1 de 8 aislamientos con resistencia fenotípica (52).

Cuando el porcentaje de resistencia de $H$. pylori a la claritromicina en una población es mayor de $15 \%$, el tratamiento de segunda línea es el cuádruple con bismuto o el de levofloxacina $(9,23)$. Sin embargo, en un estudio reciente de Trespalacios, et al., en Bogotá, se evidenció un aumento considerable de los aislamientos resistentes a la levofloxacina entre $2009(11,8 \%)$ el 2014 $(27,3 \%)(53)$. Es de gran importancia, entonces, determinar la resistencia de H. pylori a los antibióticos, con el fin de establecer esquemas terapéuticos basados en los resultados en la población colombiana para, así, disminuir la incidencia de enfermedades gastrointestinales asociadas con la infección (54).

Este es el primer estudio en el cual se describe el estado de la resistencia de $H$. pylori a la claritromicina en pacientes atendidos en Medellín; se encontró una gran prevalencia de mutaciones puntuales asociadas con dicha resistencia. Dado este hallazgo, habría que prever altos niveles de fracaso en la erradicación del microrganismo con el tratamiento triple que incluye este macrólido.

Las limitaciones del presente estudio incluyeron la falta de información sobre el consumo previo de antibióticos para tratar la infección por $H$. pylori, por lo que no se pudo diferenciar la resistencia primaria de la secundaria, así como de los detalles del informe de histopatología, tales como la carga bacteriana y el estado del epitelio gástrico; además, los participantes del estudio fueron atendidos en una sola unidad de endoscopia de la ciudad.

Se requieren más estudios para determinar la resistencia de la bacteria a los antibióticos en la población colombiana, y establecer los tratamientos de primera línea y de rescate.

\section{Agradecimientos}

Los autores agradecen a la Unidad de Endoscopia de la IPS SURA, sede Industriales, a Natalia Giraldo López, estudiante de Medicina de la Universidad de Antioquia, y a la doctora Alba Alicia Trespalacios, profesora de la Pontificia Universidad Javeriana.

\section{Referencias}

1. IARC Working Group on the Evaluation of Carcinogenic Risks to Humans. IARC monographs on the evaluation of carcinogenic risks to humans. Volume 100. A review of human carcinogens. Part B. Biological agents. Lyon: International Agency for Research on Cancer; 2012. p. 385-435.

2. Kao CY, Sheu BS, Wu JJ. Helicobacter pylori infection: An overview of bacterial virulence factors and pathogenesis. Biomed J. 2016;39:14-23. https://doi.org/10.1016/j.bj.2015.06.002 
3. Zabala B, Lucero Y, Lagomarcino AJ, Orellana-Manzano A, George S, Torres JP, et al. Prevalence and dynamics of Helicobacter pylori infection during childhood. Helicobacter. 2017;22:e12399. https://doi.org/10.1111/hel.12399

4. Hunt RH, Xiao SD, Megraud F, León-Barua R, Bazzoli F, van Der Merwe S, et al. Helicobacter pylori in developing countries. World Gastroenterology Organisation Global Guideline. J Gastrointestin Liver Dis. 2011;20:299-304.

5. Hooi JK, Lai WY, Ng WK, Suen MM, Underwood FE, Tanyingoh D, et al. Global prevalence of Helicobacter pylori Infection: Systematic review and meta-analysis. Gastroenterology. 2017;153:420-9. https://doi.org/10.1053/j.gastro.2017.04.022

6. Wroblewski LE, Peek RM, Wilson KT, Wilson KT. Helicobacter pylori and gastric cancer: Factors that modulate disease risk. Clin Microbiol Rev. 2010;23:713-39. https://doi.org/10.1128/CMR.00011-10

7. Gisbert JP. Enfermedades relacionadas con la infección por Helicobacter pylori. Gastroenterol Hepatol. 2013;36:39-50.

8. Ferlay J, Soerjomataram I, Ervik M, Dikshit R, Eser S, Mathers C, et al. GLOBOCAN 2012 v1.0, Cancer incidence and mortality worldwide: IARC Cancerbase No. 11. Lyon: International Agency for Research on Cancer; 2013.

9. Malfertheiner P, Megraud F, O'Morain CA, Gisbert JP, Kuipers EJ, Axon AT, et al. Management of Helicobacter pylori infection-the Maastricht V/Florence Consensus Report. Gut. 2017;66:6-30. https://doi.org/10.1136/gutjnl-2016-312288

10. Martínez JD, Henao SC, Lizarazo Jl. Antibiotic resistance of Helicobacter pylori in Latin America and the Caribbean. Rev Colomb Gastroenterol. 2014;29:218-27.

11. Versalovic J, Osato MS, Spakovsky K, Dore MP, Reddy R, Stone GG, et al. Point mutations in the 23S rRNA gene of Helicobacter pylori associated with different levels of clarithromycin resistance. J Antimicrob Chemother. 1997;40:283-6.

12. Trespalacios AA, Rimbara E, Otero W, Reddy R, Graham DY. Improved allele-specific PCR assays for detection of clarithromycin and fluoroquinolone resistant of Helicobacter pylori in gastric biopsies: Identification of N87I mutation in GyrA. Diagn Microbiol Infect Dis. 2015;81:251-5. https://doi.org/10.1016/j.diagmicrobio.2014.12.003

13. Ciftci IH, Ugras M, Acartekin G, Asik G, Safak B, Dilek FH. Comparison of FISH, RFLP and agar dilution methods for testing clarithromycin resistance of Helicobacter pylori. Turkish $\mathrm{J}$ Gastroenterol. 2015;25:75-80. https://doi.org/10.5152/tjg.2014.4688

14. Trespalacios AA, Otero W, Caminos JE, Mercado MM, Ávila J, Rosero LE, et al. Phenotypic and genotypic analysis of clarithromycin-resistant Helicobacter pylori from Bogotá, D.C., Colombia. J Microbiol. 2013;51:448-52. https://doi.org/10.1007/s12275-013-2465-6

15. Kim KS, Kang JO, Eun CS, Han DS, Choi TY. Mutations in the 23S rRNA gene of Helicobacter pylori associated with clarithromycin resistance. J Korean Med Sci. 2002;17:599-603. https://doi.org/10.3346/jkms.2002.17.5.599

16. Trespalacios AA, Otero-Regino W, Mercado-Reyes M. Helicobacter pylori resistance to metronidazole, clarithromycin and amoxicillin in Colombian patients. Rev Colomb Gastroenterol. 2010;25:29-36.

17. Bravo LE, Cortés A, Carrascal E, Jaramillo R, García LS, Bravo PE, et al. Helicobacter pylori: patología y prevalencia en biopsias gástricas en Colombia. Colomb Med. 2003;34:124-31.

18. Lee YC, Liou JM, Wu MS, Wu CY, Lin JT. Eradication of Helicobacter pylori to prevent gastroduodenal diseases: Hitting more than one bird with the same stone. Therap Adv Gastroenterol. 2008;1:111-20. https://doi.org/10.1177/1756283X08094880

19. Instituto Nacional de Salud. Quinto Informe ONS: carga de enfermedad por enfermedades crónicas no transmisibles y discapacidad en Colombia. Quinta edición. Bogotá: Instituto Nacional de Salud; 2015.

20. Regino WO. La importancia de cultivar Helicobacter pylori. Rev Colomb Gastroenterol. 2013;28:87-92

21. Sierra F, Forero JD, Rey M. Tratamiento ideal del Helicobacter pylori: una revisión sistemática. Rev Gastroenterol Mex. 2014;79:28-49. https://doi.org/10.1016/j.rgmx.2013.03.003

22. Gómez M, Ruíz O, Páramo-Hernández D, Albis R, Sabbagh LC. Erradicación del Helicobacter pylori: encuesta realizada por la Asociación Colombiana de Gastroenterología. Rev Col Gastroenterol. 2015;30:25-31. 
23. Camargo MC, García A, Riquelme A, Otero W, Camargo CA, Hernández-García T, et al. The problem of Helicobacter pylori resistance to antibiotics: A systematic review in Latin America. Am J Gastroenterol. 2014;109:485-95. https://doi.org/10.1038/ajg.2014.24

24. Di Ciaula A, Scaccianoce G, Venerito M, Zullo A, Bonfrate L, Rokkas T, et al. Eradication rates in italian subjects heterogeneously managed for Helicobacter pylori infection. Time to abandon empiric treatments in Southern Europe. J Gastrointest Liver Dis. 2017;26:129-37. https://doi.org/10.15403/jgld.2014.1121.262.itl

25. Castaño R, Ruiz-Vélez MH, Martínez-Hincapié C, Naranjo-Aristizábal FA, Campuzano-Maya G, Sanín-Fonnegra E, et al. Evaluación para comparar dos esquemas de terapia estándar (7 frente a 10 días) contra el Helicobacter pylori, con seguimiento clínico a 1 año. Rev Colomb Gastroenterol. 2012;27:80-7.

26. Castaño R, Ruiz-Vélez MH, Campuzano-Maya G, Sanín-Fonnegra E, Puerta-Díaz JD, Calvo-Betancur V, et al. Randomized study comparing standard first line 10 day therapy against Helicobacter pylori including clarithromycin versus standard first line therapy with levofloxacin. Rev Colomb Gastroenterol. 2013;28:101-8.

27. Correa S, Cardona AF, Correa T, Correa LA, García HI, Estrada S. Prevalence of Helicobacter pylori and histopathological features in gastric biopsies from patients with dyspeptic symptoms at a referral center in Medellín. Rev Colomb Gastroenterol. 2016;31:915.

28. Peixoto A, Silva M, Pereira P, Macedo G. Biopsies in gastrointestinal endoscopy: When and how. GE Port J Gastroenterol. 2016;23:19-27. https://doi.org/10.1016/j.jpge.2015.07.004

29. Genta RM, Graham DY. Comparison of biopsy sites for the histopathologic diagnosis of Helicobacter pylori: A topographic study of $H$. pylori density and distribution. Gastrointest Endosc. 1994;40:342-5. https://doi.org/10.1016/S0016-5107(94)70067-2

30. Acosta CP, Hurtado FA, Trespalacios AA. Determinación de mutaciones de un solo nucleótido en el gen 23S rRNA de Helicobacter pylori relacionadas con resistencia a claritromicina en una población del departamento del Cauca, Colombia. Biomédica. 2013;34:156-62. https://doi.org/10.7705/biomedica.v34i0.1649

31. Occhialini A, Urdaci M, Doucet-Populaire F, Bébéar CM, Lamouliatte H, Mégraud F. Macrolide resistance in Helicobacter pylori: Rapid detection of point mutations and assays of macrolide binding to ribosomes. Antimicrob Agents Chemother. 1997;41:2724-8. https://doi.org/10.1128/AAC.41.12.2724

32. Rendón JC, Cortés-Mancera F, Restrepo-Gutiérrez JC, Hoyos S, Navas MC. Molecular characterization of occult hepatitis $B$ virus infection in patients with end-stage liver disease in Colombia. PLoS One. 2017;12:e0180447. https://doi.org/10.1371/journal.pone.0180447

33. Patel SK, Pratap CB, Jain AK, Gulati AK, Nath G. Diagnosis of Helicobacter pylori: What should be the gold standard? World J Gastroenterol. 2014;20:12847-59. https://doi.org/10.3748/wjg.v20.i36.12847

34. Jiménez F, Barbaglia Y, Bucci P, Tedeschi FA, Zalazar FE. Detección molecular y genotipificación de Helicobacter pylori en biopsias gástricas de pacientes adultos sintomáticos de la ciudad de Santa Fe, Argentina. Rev Argent Microbiol. 2013;45:39-43.

35. Wang YK, Kuo FC, Liu CJ, Wu MC, Shih HY, Wang SS, et al. Diagnosis of Helicobacter pylori infection: Current options and developments. World J Gastroenterol. 2015;21:1122135. https://doi.org/10.3748/wjg.v21.i40.11221

36. de Martel C, Plummer M, van Doorn LJ, Vivas J, López G, Carillo E, et al. Comparison of polymerase chain reaction and histopathology for the detection of Helicobacter pylori in gastric biopsies. Int J Cancer. 2010;126:1992-6. https://doi.org/10.1002/ijc.24898

37. Cosgun Y, Yildirim A, Yucel M, Karakoc AE, Koca G, Gonultas A, et al. Evaluation of invasive and noninvasive methods for the diagnosis of Helicobacter pylori infection. Asian Pac $J$ Cancer Prev. 2016;17:6165-72. https://doi.org/10.22034/APJCP.2016.17.12.5265

38. Hammar M, Tyszkiewicz T, Wadström T, O'Toole PW. Rapid detection of Helicobacter pylori in gastric biopsy material by polymerase chain reaction. J Clin Microbiol. 1992;30:54-8.

39. Ahmad N, Zakaria WR, Abdullah SA, Mohamed R. Characterization of clarithromycin resistance in Malaysian isolates of Helicobacter pylori. World J Gastroenterol. 2009;15:3161-5. https://doi.org/10.3748/wjg.15.3161

40. Yula E, Nagiyev T, Kaya ÖA, Inci M, Çelik MM, Köksal F. Detection of primary clarithromycin resistance of Helicobacter pylori and association between cagA + status and clinical outcome. Folia Microbiol (Praha). 2013;58:141-6. https://doi.org/10.1007/s12223-012-0192-8 
41. Mahmoudi S, Mamishi S, Banar M, Keshavarz Valian S, Bahador A, Najafi M, et al. Antibiotic susceptibility of Helicobacter pylori strains isolated from Iranian children: High frequency of A2143G point mutation associated with clarithromycin resistance. J Glob Antimicrob Resist. 2017;10:131-5. https://doi.org/10.1016/j.jgar.2017.04.011

42. Abdollahi H, Savari M, Zahedi MJ, Moghadam SD, Abasi MH. Detection of A2142C, A2142G, and A2143G mutations in 23s rRNA gene conferring resistance to clarithromycin among Helicobacter pylori isolates in Kerman, Iran. Iran J Med Sci. 2011;36:104-10.

43. Pourakbari B, Mahmoudi S, Parhiz J, Sadeghi RH, Monajemzadeh M, Mamishi S. High frequency of metronidazole and clarithromycin-resistant Helicobacter pylori in formalin-fixed, paraffin-embedded gastric biopsies. Br J Biomed Sci. 2018;75:61-5. https://doi.org/10.1080/09674845.2017.1391466

44. Henao SC, Quiroga A, Martínez JD, Otero W. Resistencia primaria a la claritromicina en aislamientos de Helicobacter pylori. Rev Colomb Gastroenterol. 2009;24:110-4.

45. Figueroa M, Cortés A, Pazos A, Bravo LE. Susceptibilidad in vitro de Helicobacter pylori a amoxicilina y claritromicina obtenido a partir de biopsias gástricas de pacientes de zona de bajo riesgo para cáncer gástrico. Biomédica. 2012;32:32-42. https://doi.org/10.7705/biomedica.v32i1.454

46. Yepes CA, Rodríguez A, Ruiz Á, Ariza B. Antibiotics resistance of Helicobacter pylori at the San Ignacio University Hospital in Bogotá. Acta Medica Colomb. 2008;33:11-4.

47. Álvarez A, Moncayo JI, Santacruz JJ, Corredor LF, Reinosa E, Martínez JW, et al. Resistencia a metronidazol y claritromicina en aislamientos de Helicobacter pylori de pacientes dispépticos en Colombia. Rev Med Chil. 2009;137:1309-14. https://doi.org/10.4067/S0034-98872009001000005

48. Álvarez A, Moncayo JI, Santacruz JJ, Santacoloma M, Corredor LF, Reinosa E. Antimicrobial susceptibility and mutations involved in clarithromycin resistance in Helicobacter pylori isolates from patients in the western central region of Colombia. Antimicrob Agents Chemother. 2009;53:4022-4. https://doi.org/10.1128/AAC.00145-09

49. Bustamante-Rengifo JA, Matta AJ, Pazos A, Bravo LE. In vitro effect of amoxicillin and clarithromycin on the 3' region of cagA gene in Helicobacter pylori isolates. World $\mathrm{J}$ Gastroenterol. 2013;19:6044-54. https://doi.org/10.3748/wjg.v19.i36.6044

50. Sanches BS, Martins GM, Lima K, Cota B, Moretzsohn LD, Ribeiro LT, et al. Detection of Helicobacter pylori resistance to clarithromycin and fluoroquinolones in Brazil: A national survey observational study. World J Gastroenterol. 2016;22:7587-94. https://doi.org/10.3748/wjg.v22.i33.7587

51. Zerbetto G, Mendiondo N, Wonaga A, Viola L, Ibarra D, Campitelli E, et al. Occurrence of mutations in the antimicrobial target genes related to levofloxacin, clarithromycin, and amoxicillin resistance in Helicobacter pylori isolates from Buenos Aires City. Microb Drug Resist. 2016;23:351-8. https://doi.org/10.1089/mdr.2015.0361

52. Alarcón-Millán J, Fernández-Tilapa G, Cortés-Malagón EM, Castañón-Sánchez CA, De Sampedro-Reyes J, Cruz-del Carmen I, et al. Clarithromycin resistance and prevalence of Helicobacter pylori virulent genotypes in patients from Southern México with chronic gastritis. Infect Genet Evol. 2016;44:190-8. https://doi.org/10.1016/j.meegid.2016.06.044

53. Trespalacios-Rangel AA, Otero W, Arévalo-Galvis A, Poutou-Piñales RA, Rimbara E, Graham DY. Surveillance of levofloxacin resistance in Helicobacter pylori isolates in Bogotá-Colombia (2009-2014). PLoS One. 2016;11:e0160007. https://doi.org/10.1371/journal.pone.0160007

54. Thung I, Aramin H, Vavinskaya V, Gupta S, Park JY, Crowe SE, et al. Review article: The global emergence of Helicobacter pylori antibiotic resistance. Aliment Pharmacol Ther. 2016;43:514-33. https://doi.org/10.1111/apt.13497 